\title{
Intensive enteral feeding in advanced cirrhosis: reversal of malnutrition without precipitation of hepatic encephalopathy
}

\author{
C P J Charlton, E Buchanan, C E Holden, M A Preece, A Green, I W Booth, M J Tarlow
}

\begin{abstract}
Ten children with advanced cirrhosis and malnutrition ( $<90 \%$ weight for height) were fed for eight weeks with a nasogastric feed comprising whey protein (enriched with branched chain amino acids), fat as $34 \%$ medium chain and $66 \%$ long chain triglycerides, and glucose polymer. Six of the children were studied for an eight week control period before feeding. Weight, triceps skinfold thickness, mid-arm circumference, mid-arm muscle area, and fasting plasma ammonia and amino acid concentrations were measured before and after the control period and after the consequent feed period. Results showed that despite high energy and protein intakes the children remained malnourished over the control period. All anthropometric indices improved significantly during the feed period, and no child developed clinical encephalopathy. The feed period was associated with a small, and not clinically significant, increase in the plasma ammonia concentration, but no consistent trend in the plasma amino acid concentrations. Thus, in children with advanced hepatobiliary disease awaiting liver transplantation, enteral feeding improved nutritional status without adverse clinical or biochemical effects.
\end{abstract}

Institute of Child Health, University of

Birmingham

C P J Charlton

I W Booth

M J Tarlow

Children's Hospital,

Birmingham

E Buchanan

C E Holden

M A Preece

A Green

Correspondence to:

Dr C P J Charlton,

Joint Academic Department, Queen Elizabeth Hospital

for Children, Hackney Road,

London E2 8PS.

Accepted 4 February 1992

Malnutrition is common in children with hepatobiliary disease. ${ }^{1} 2$ It may be associated with a number of adverse effects such as decreased brain growth, ${ }^{3} 4$ impairment of mental development, ${ }^{3}$ and decreased immunocompetence ${ }^{5}$ with an increased susceptibility to infection. ${ }^{6}$ The pathogenesis of malnutrition in liver disease is poorly understood. Anorexia, ${ }^{7}$ increased metabolic rate, ${ }^{8}$ and fat malabsorption ${ }^{9}$ are all potentially important contributory factors and raise the possibility that reversal of malnutrition may occur with appropriate intensive nutritional support. We have addressed this question with a study of intensive enteral nutrition in a

Details of subjects

\begin{tabular}{|c|c|c|c|c|}
\hline $\begin{array}{l}\text { Case } \\
\text { No }\end{array}$ & Diagnosis & $\begin{array}{l}\text { Age } \\
\text { (years) }\end{array}$ & $\begin{array}{l}\text { Bilirubin } \\
(\text { /mol/ll })\end{array}$ & $\begin{array}{l}\text { Albumin } \\
(\mathrm{g} / \mathrm{l})\end{array}$ \\
\hline $\begin{array}{r}1 \\
2 \\
3 \\
4 \\
5 \\
6 \\
7 \\
8 \\
9 \\
10\end{array}$ & $\begin{array}{l}\text { Biliary atresia } \\
\text { Biliary atresia } \\
\text { Neonatal hepatitis/cirrhosis } \\
\text { Biliary atresia } \\
\alpha_{1} \text {-antitrypsin deficiency } \\
\text { Biliary atresia } \\
\text { Neonatal hepatitis/cirrhosis } \\
\text { Biliary atresia } \\
\text { Biliary atresia } \\
\alpha_{1} \text {-antitrypsin deficiency }\end{array}$ & $\begin{array}{l}0.5 \\
1.92 \\
0.83 \\
0.67 \\
2 \cdot 42 \\
0.83 \\
0.83 \\
7.92 \\
0.67 \\
0.33\end{array}$ & $\begin{array}{r}140 \\
70 \\
15 \\
260 \\
40 \\
190 \\
190 \\
30 \\
250 \\
170\end{array}$ & $\begin{array}{l}39 \\
30 \\
25 \\
31 \\
24 \\
35 \\
35 \\
35 \\
29 \\
43\end{array}$ \\
\hline
\end{tabular}

group of children with severe chronic liver disease. Such an intervention in patients with advanced liver disease might be expected to exacerbate already impaired nitrogen tolerance ${ }^{10}$ and precipitate hepatic encephalopathy. ${ }^{11}$ Moreover, fat malabsorption is well recognised in children with cholestatic liver disease, ${ }^{12} 13$ and an increase in dietary lipid might be expected to precipitate diarrhoea. However, there is some evidence that a nitrogen load high in branched chain amino acids may be less likely than a simple high protein diet to exacerbate such abnormalities or to precipitate hepatic coma. ${ }^{14}$ Similarly, medium chain triglycerides may be better tolerated than long chain triglycerides in patients with chronic liver disease. ${ }^{9}$ We therefore used a modular feed in which the nitrogen source was enriched with branched chain amino acids and the lipid source was a mixture of long and medium chain triglycerides. We performed an open controlled study with two aims. First, to determine whether malnutrition complicating advanced cirrhosis could be reversed by short term intensive enteral feeding lasting eight weeks. Second, to establish whether such an intervention was associated with dangerous clinical or biochemical sequelae.

\section{Subjects and methods}

Ten children (median age 9 months, range 4 months to 8 years; six boys and four girls) were studied. All 10 had cirrhosis that had been proved at biopsy. The plasma bilirubin and albumin concentrations at the start of the study and the aetiology are shown in the table. All were less than $90 \%$ of their expected weight for height (range 62-88\%, median 78\%). ${ }^{15} 16$ Three had ascites at the start of the study and five had oesophageal varices.

Six of the children were observed over an eight week control period on their own diet before the eight week period on the trial diet. Such a control period was not possible in four children, who presented urgently to hospital and started immediately on enteral feeding.

The study was approved by the local research ethical committee and all parents gave their informed consent.

\section{DIETARY ASSESSMENT}

Nutrient intake before enteral feeding was assessed using seven day weighed records by parents and subsequent computer analysis of the dietary records. ${ }^{17}$ Recall dietary assessment at home before feeding and dietetic advice given were noted for the other three children. 
ENTERAL FEED

A modular feed was used. The nitrogen source (Generaid, Scientific Hospital Supplies) was whey, enriched with free branched chain amino acids (whey protein $73 \%$, and free branched chain amino acids $27 \%$, in protein gram equivalents). The total branched chain amino acid content of the protein was $31 \%$ (including branched chain amino acid content of whey). Each child received $4 \mathrm{~g} / \mathrm{kg} /$ day of protein. Fat, comprising $34 \%$ medium chain triglyceride and $66 \%$ long chain triglyceride, and carbohydrate (as glucose polymer) were given as Duocal (Scientific Hospital Supplies). Energy content of the feed was $8 \%$ protein, $40 \%$ fat, and $52 \%$ carbohydrate. Vitamin and mineral requirements were provided for children under 1 year old as Paediatric Seravit (Scientific Hospital Supplies) which contains no sodium or potassium, and for those over 1 year old as Code 544 (Scientific Hospital Supplies) which contains no sodium, potassium, calcium, or phosphate. Sodium and potassium were provided as molar solutions and calcium and phosphate as Calcium-Sandoz and Phosphate-Sandoz (Sandoz). All subjects received additional supplements of vitamins A, D, and E. Initial feed volumes were calculated to provide either $140 \%$ of the previous energy intake or $140 \%$ of recommended energy requirements per. $\mathrm{kg}$ for age ${ }^{18}$ whichever was greater. The energy density of the feed ranged between 1 and $1.5 \mathrm{kcal} / \mathrm{ml}$ depending on the fluid allowance for the child, with a mean osmolality of $400 \mathrm{mosmol} / \mathrm{kg}$.

\section{ADMINISTRATION OF FEED}

Feeding was started in hospital and given by continuous nasogastric infusion over 18-22 hours/day. The initial protein content of the feed was the same as the intake during the control period when this information was available or at $1 \mathrm{~g} / \mathrm{kg} /$ day where not available. Intake was increased by $1 \mathrm{~g}$ per kg per day every third day to a maximum of $4 \mathrm{~g} / \mathrm{kg} / \mathrm{day}$. The carbohydrate and fat components were also increased stepwise until final energy requirements were reached by five days. The children were encouraged to have additional food during the study period but none took a significant amount. The parents were taught to make up the feed, to care for the nasogastric tube (6FG Silk, $\mathrm{E}$ Merck), and to control the infusion pump (Kangaroo Pump, Sherwood Medical) before their child was discharged. ${ }^{19}$ The feed was given for eight weeks; blood samples were obtained and anthropometric recordings taken at the start and the end of this period. The children were examined for ascites and signs of hepatic encephalopathy at least every two weeks and the nutrient intake per $\mathrm{kg}$ body weight maintained throughout the eight week period.

\section{ANTHROPOMETRY}

Measurements were carried out by one observer (CPJC) using the same balance scales (weighing to nearest $25 \mathrm{~g}$ ), non-stretch plastic tape, Holtain skinfold calipers, and Holtain stadiometer. Triceps skinfold thickness was measured half way between the tip of the acromion process and the tip of the olecranon of the relaxed left arm. The upper mid-arm circumference was measured at the same point. The measurements were expressed as standard deviation (SD) scores. ${ }^{20}$ The following standards were used: Sann et al (1988) for arm anthropometry under 1 year old, ${ }^{21}$ Tanner (1973) for weight and length for all ages and triceps skinfold thickness above 1 year old, ${ }^{15}$ and Frisancho (1981) for mid-arm circumference and mid-arm muscle area above one year. ${ }^{22}$ The mid-arm muscle area was calculated from the mid-arm circumference and the triceps skinfold thickness ${ }^{23}$ and expressed as a percentage of the median of the reference population. Measurements were carried out before and after the eight week control period, and again at the end of the subsequent eight week feeding period for six of the 10 children. For the other four children measurements were carried before and after the feeding period.

\section{BIOCHEMISTRY}

Venous blood was taken after a four hour fast at the same time as anthropometry. Plasma ammonia concentration was assayed by a continuous flow ion selective electrode system. ${ }^{24}$ Plasma for amino acid analysis was deproteinised immediately after collection by the addition of an equal volume of $3 \%$ sulphosalicyclic acid. The supernatant was stored at minus $20^{\circ} \mathrm{C}$ until analysis. Amino acids were measured by ion exchange chromatography using a lithium buffer system and ninhydrin detection (Kontron Chromakon 500). The reference standards used were Brodehl and Gellissen ${ }^{25}$ and Scriver and Davies. ${ }^{26}$

\section{STATISTICAL METHODS}

The Wilcoxon signed rank test was used to compare the paired results. Comparisons between the feed and control periods entered the analysis as a quadratic time component. The significance of this comparison was assessed using a repeated measures analysis of variance. Raw data was used for this analysis apart from ammonia concentrations where logarithmic transformation was performed.

\section{Results}

DIETARY ASSESSMENT

Seven children had dietary assessments before enteral feeding. Energy intakes were 90 to $165 \%$ (mean 130\%) of the recommended intake per kg for age ${ }^{18}$ and protein intakes 2.6 to $5.7 \mathrm{~g} / \mathrm{kg} /$ day (median $3.4 \mathrm{~g} / \mathrm{kg} / \mathrm{day}$ ). Six children had intakes above that recommended by the World Health Organisation, and these were fed $140 \%$ of their recorded intake for the feeding period. The other four children received $140 \%$ of their recommended energy intake. Before the trial four children were on normal diets, four were taking energy supplements (carbohydrate and medium chain triglycerides), and two were on Pregestimil (Bristol-Myers), one .of whom was also on energy supplementation. Nine of the 
children had dietetic advice to maximise energy intake.

TOLERANCE OF FEEDING

Both the nasogastric tube and the enteral feed were well tolerated with no adverse clinical events. In particular, diarrhoea was not a problem. Regurgitation, which had been present before the trial, was exacerbated in two infants but lessened with feed thickening. If the polyurethane nasogastric tube continued to be displaced frequently by the vomiting it was replaced by a stiffer polyvinylchloride tube (Portex). None of the 10 children developed fluid overload (development or exacerbation of ascites and/or peripheral oedema). Two of the three with ascites before feeding had lost it by the end of the feed period. The modular nature of the feed allowed precise control of fluid and sodium intake, which aided the control of the ascites. There were no episodes of variceal haemorrhage. All 10 children maintained their target intakes throughout the eight week period.

\section{ANTHROPOMETRY}

The weight, mid-arm circumference, and midarm muscle area before the eight week control period, where available, and before and after the consequent eight week feeding period are shown in fig 1. Malnutrition was severe before feeding, and nine of the children were more than 2 SDs below the reference mean for midarm circumference. All children increased their weight, triceps skinfold thickness, mid-arm circumference, and arm muscle area during the feed period and these changes were statistically significant $(p<0.005)$. Statistically significant improvements over the intervention period compared with the control period were obtained for all measurements (weight $\mathrm{p}<0.005$; midarm circumference, triceps skinfold thickness, and arm muscle area $p<0.001$ ).

\section{BIOCHEMICAL MEASUREMENTS}

Individual plasma ammonia concentrations at the start of the eight week control period and before and after the eight week feed period are shown in fig 2. Prefeeding plasma ammonia concentrations in eight out of the 10 children were above the laboratory reference range for well children. Analysis of the changes in ammonia concentration both during the feed period and between the control and feed period were statistically significant $(p<0 \cdot 05)$. However, there was much variance in the data and the concentrations never approached those usually associated with clinical problems. ${ }^{27}$ No patient developed hepatic encephalopathy, and no parent reported increased drowsiness in their child. Indeed, nine out of the 10 children were reported by parents to have become more active and lively during the trial.

The mean fasting plasma amino acid concentrations before and after feeding are shown in fig 3. Concentrations are expressed as the number of SDs from the reference mean for the age band. The majority of amino acid concentrations were in the normal range before feeding
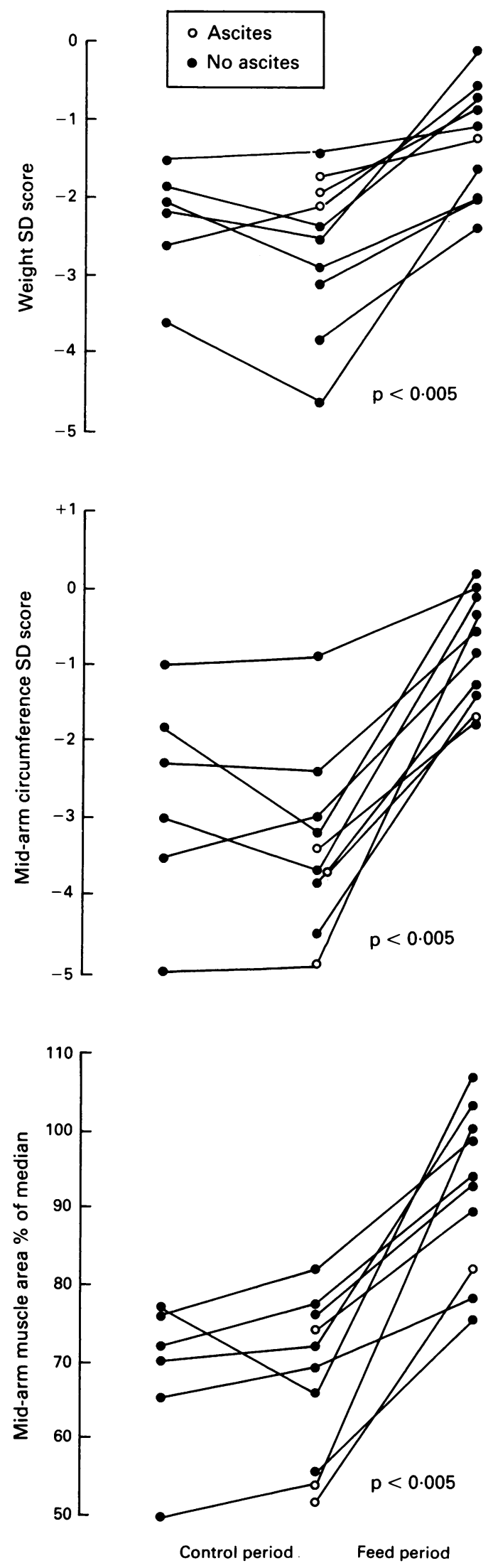

Figure 1 Changes in weight SD scores, mid-arm circumference $S D$ scores, and mid-arm muscle area as \% of median (see text for reference population standards) for six children with cirrhosis over the eight week control period and all 10 subjects over the eight week intensive enteral feeding period. Prefeed versus postfeed: weight SD score, mid-arm circumference $S D$ score, and mid-arm muscle area all $<0.005$. Change in parameters over feed period were $<0 \cdot 005$. Change in parameters over feed period were
significantly different from change over control period: weight $S D$ score $<0.005$; mid-arm circumference $S D$ score, and mid-arm muscle area \% of median $p<0.001$. 


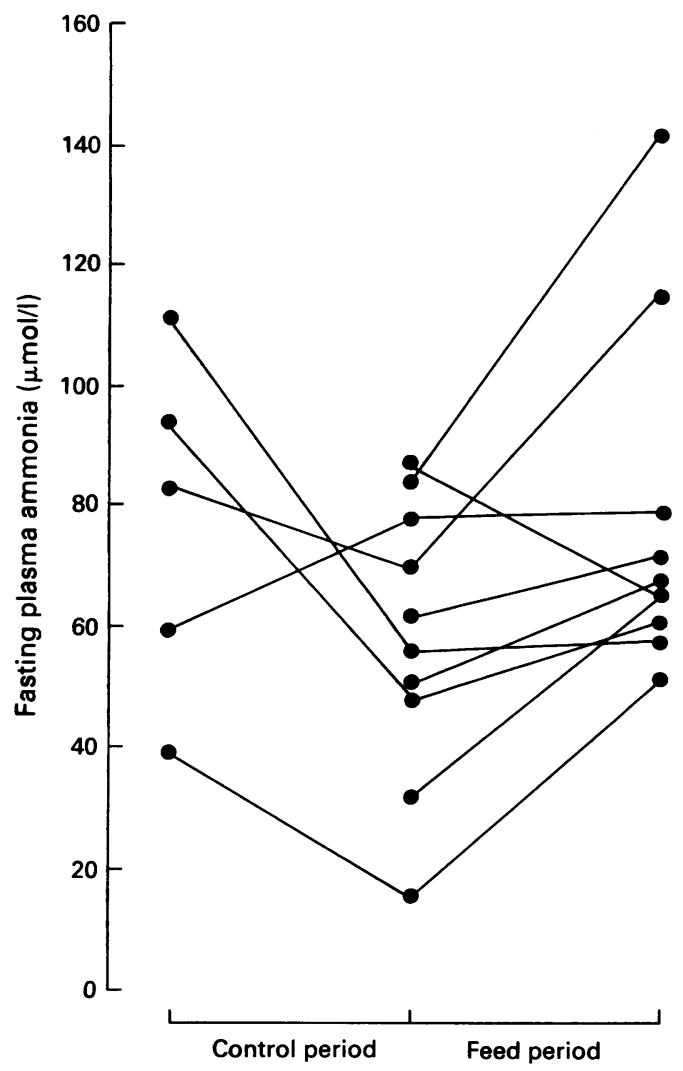

Figure 2 Fasting plasma ammonia concentrations before and after eight week control period and after consequent enteral feeding period in children with cirrhosis. Upper limi of laboratory reference range ( $95 \%$ confidence limits) is $40 \mu \mathrm{mol} / \mathrm{l}$. Analysis of the paired results before and after the feed period and the change over control period compared with that over the feed period gave $p<0.05$ for both.

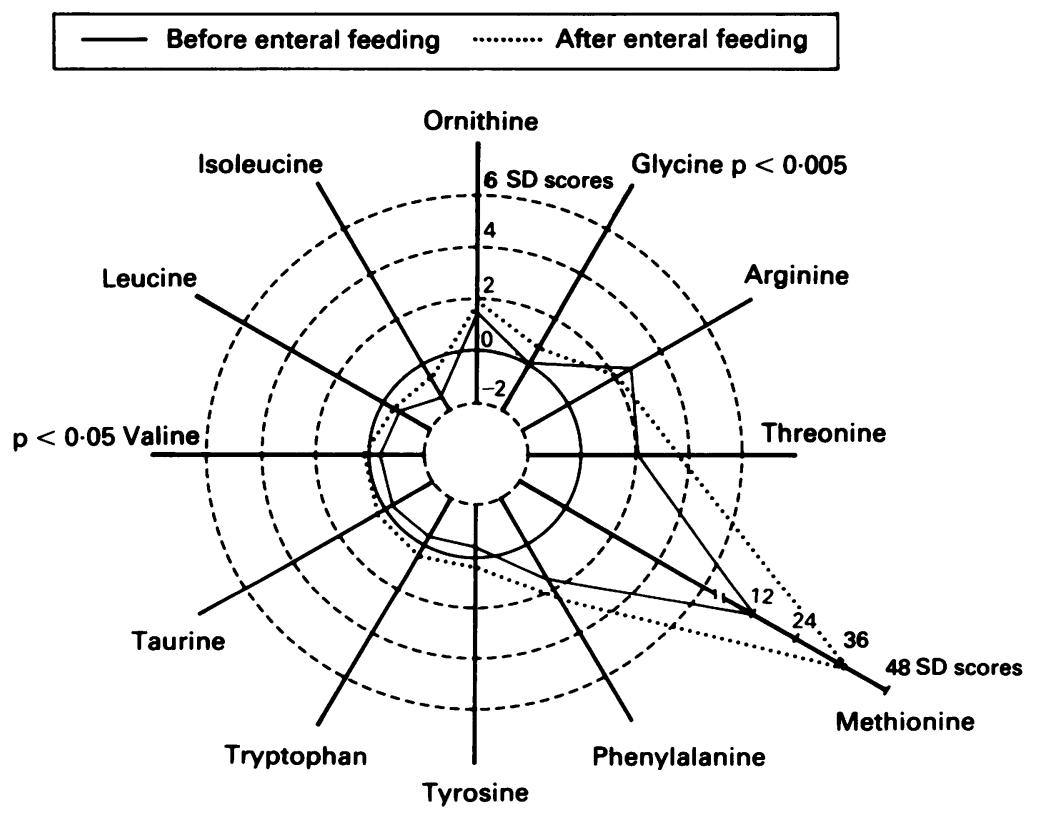

Figure 3 Changes in mean fasting amino acid concentrations of 10 children with cirrhosis before and after eight weeks of enteral feeding expressed as a SD score of reference standards. ${ }^{25}{ }^{26}$ The bold circle represents the mean amino acid concentration for the reference population. The dashed concentric circles represent $2 S D$ steps from the reference mean. (Methionine has an extended scale.) Individual amino acids values are plotted on the radii of the diagram. Analysis of the individual paired results before and after feeding for the amino acids shown (and also glutamine, aspartate, cystine, serine, alanine, proline, and lysine) were statistically non-significant apart from valine, $p<0.05$ and glycine, $p<0.005$.

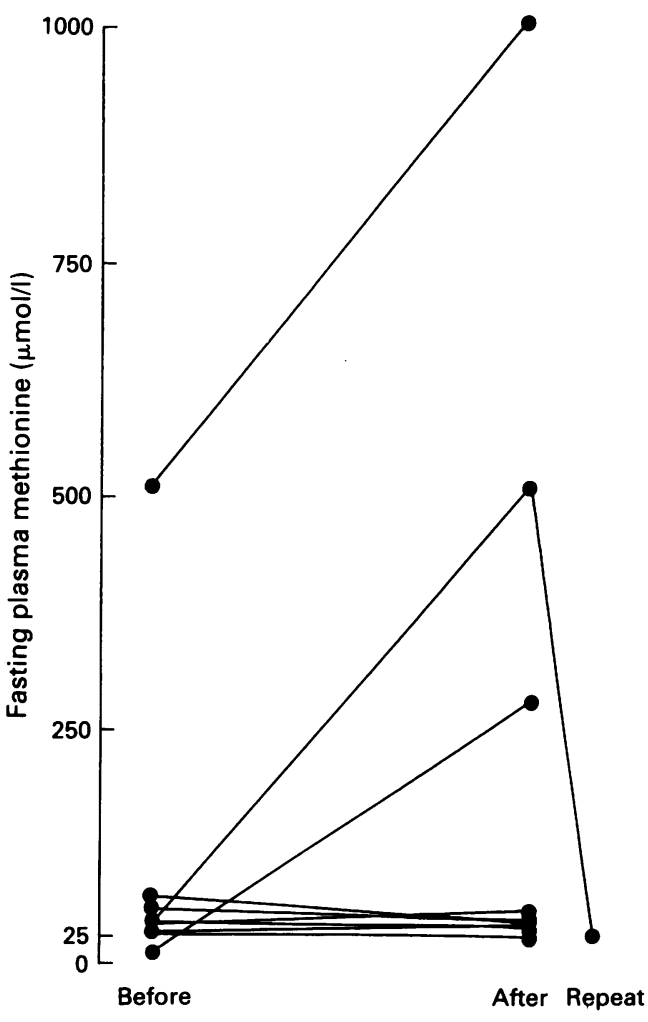

Figure 4 Fasting plasma methionine concentrations for 10 children with cirrhosis before and after the eight week enteral feeding period with a repeat result for an individual (still on the trial regimen) who had an intercurrent viral infection at the time of the eight week sample. Analysis of the paired results was not significant.

$(-2$ to +2 SD) and were unchanged afterwards. In particular branched chain amino acids were all near the reference mean both before and after feeding. Lysine, threonine, and phenylalanine concentrations were above the reference range initially, but did not increase after feeding. Mean methionine concentrations were raised both before and after feeding, a finding consistent with severe liver disease. While the mean methionine concentration was higher at the end of feed period than before, there was no statistically significant difference between the individual paired results. This rise was biased by the results in three children in whom methionine concentrations increased greatly. Two of those three had deteriorating liver function during the study as determined by prolongation of prothrombin time. The third child had an intercurrent viral infection in week 8 of the feed period at the time of the second sample, and a repeat methionine concentration after recovery while still on nasogastric feeding was similar to the prefeed value (fig 4). The other seven children had appreciably raised methionine concentrations up to 9 SDs above the reference mean both before and after feeding with little individual change.

\section{Discussion}

Intensive enteral feeding appreciably improved the nutritional status of the children, assessed clinically by upper arm measurements and by weight. There were no serious deleterious effects. In particular, no episodes of hepatic 
encephalopathy were precipitated. Although the children studied were malnourished, we found no evidence of a poor dietary intake. This differs from the observations of Watkins and Glassman. ${ }^{7}$ The majority of children we studied had received dietary advice aimed at increasing energy intake before feeding and had an energy intake higher than that recommended for age and weight. ${ }^{18}$ Our sample was small but these observations point to malabsorption, poor utilisation, or increased metabolic requirements as more important mechanisms for protein energy malnutrition than inadequate intake. This is supported by the demonstration of Pierro et al that children with extrahepatic biliary atresia have both an increased resting energy expenditure and large energy losses in the stools. ${ }^{8}$

Fasting plasma ammonia concentrations were above the reference range before feeding and had risen further by the end of the study period. However, this was not associated with any clinical deterioration and the concentrations were much lower than seen for example in Reye's syndrome. ${ }^{28}$ This study had small patient numbers and until more data and clinical follow up are available, we would advise clinical observation for adverse effects and measuring plasma ammonia in situations where dietary nitrogen is being increased in children with severe liver disease.

The amino acid profiles before feeding showed similar abnormalities to those documented previously, ${ }^{10}$ with particular elevations of methionine, threonine, and phenylalanine. Branched chain amino acid concentrations were in the reference range. This pattern changed little with enteral feeding and there were no increases in branched chain amino acid concentrations. Thus, in the group studied, no gross abnormality was attributable to the high nitrogen load. In this study we have demonstrated that malnutrition in children with cirrhosis occurs despite a normal or high energy intake; it can be reversed without deleterious effects by an intensive period of enteral feeding. However, we cannot conclude that branched chain amino acid enrichment has any advantage over standard protein and this will require further study.

The only chance of long term survival for these children is liver transplantation. We speculate that better nourished children will have improved survival before transplantation during their wait for a donor organ. In one centre, $25 \%$ of children died while awaiting transplantation. ${ }^{29}$ Poor pretransplant nutrition may also be associated with an adverse result after grafting. ${ }^{30}$ Prior correction of severe protein energy malnutrition may therefore improve the long term outlook of children with severe liver disease awaiting transplantation.
We thank Alan Girling, School of Mathematics and Statistics, University of Birmingham, for statistical advice; Scientific Hospital Supplies, Liverpool for supply of the feed components; and 'Remember Rebecca Trust' for provision of computer equipment.

1 Kaufman SS, Murray ND, Wood RP, Shaw BW, Vanderoof JA. Nutritional support for the infant with extrahepatic biliary atresia. $\mathcal{F}$ Pediatr 1987;110:679-86.

2 Stewart SM, Uauy R, Kennard BD, Waller DA, Benser M, Andrews WS. Mental development and growth in children with chronic liver disease of early and late onset. Pediatrics with chronic liver

3 Sokal RJ, Stall C. Anthropometric evaluation of children with chronic liver disease. Am $\mathcal{F}$ Clin Nutr 1990;52:203-8.

4 Winick M, Rosso P. Head circumference and cellular growth of the brain in normal and marasmic children. $\mathcal{F}$ Pediat 1969;74:774-8.

5 Chandra RK. Nutrition, immunity and infection: presen knowledge and future directions. Lancet 1983;i:688-91.

6 O'Keefe SJ, El-Zayadi AR, Carraher TE, Davis M, William R. Malnutrition and immunocompetence in patients with liver disease. Lancet 1980;ii:615-7.

7 Watkins JB, Glassman MS. Acute and chronic liver disease. In: Walker WA, Watkins JB, eds. Nutrition in pediatrics. Boston: Little, Brown and Company, 1985:485-96.

8 Pierro A, Koletzko B, Carnelli V, et al. Resting energy expenditure is increased in infants and children with extrahepatic biliary atresia. 7 Pediatr Surg 1989;24:534-8.

9 Burke V, Danks DM. Medium-chain triglyceride diet: its use in treatment of liver disease. $B M \mathcal{F}$ 1966;ii: $1050-1$.

10 Weisdorf SA, Freese DK, Fath JJ, Tsai MY, Cerra FB. Amino acid abnormalities in infants with extrahepatic Amino acid abnormalities in infants with extrahepatic biliary atresia

11 Munro HN, Fernstrom JD, Wurtman RJ. Insulin, plasma amino acid imbalance, and hepatic coma. Lancet 1975; 772-4.

12 Weber A, Roy CC. The malabsorption associated with chronic liver disease in children. Pediatrics 1972;50:73-83.

13 Glasgow JFT, Hamilton JR, Sass-Kortsak A. Fat absorption in congenital obstructive liver disease. Arch Dis Child 1973;48:601-7.

14 Maddrey WC. Branched amino acid therapy in liver disease. 7 Am Coll Nutr 1985;4:639-50.

15 Tanner JM. Physical growth and development. In: Forfar JO, Arneil GC, eds. Textbook of paediatrics. London: Churchill-Livingstone, 1973:442-5.

16 Waterlow JC. Note on the assessment and classification of protein-energy malnutrition in children. Lancet 1980;ii: p7-9.

17 Bassham S, Fletcher LR, Stanton RHJ. Dietary analysis with the aid of a microcomputer. Foumal of Microcomputer Applications 1984;7:279-89.

18 World Health Organisation. Energy and protein requirements. Report of a joint FAO/WHO/UNU meeting. WHO Tech Rep Ser No 724, Geneva: WHO, 1985.

19 Holden CE, Puntis JWL, Charlton CPJ, Booth IW. Home enteral nutrition: acceptability and safety. Arch Dis Child 1991;66:148-51.

20 WHO Working Group. Use and interpretation of anthropometric indicators of nutritional status. Bull World Health Organ 1986;64:929-41.

21 Sann L, Durand M, Picard J, Lasne Y, Bethenod M. Arm fat and muscle areas in infancy. Arch Dis Child 1988;63: 256-60.

22 Frisancho AR. New norms of upper limb fat and muscle areas for assessment of nutritional status. Am $\mathcal{J}$ Clin Nutr for assessment

23 Gurney JM, Jelliffe DB. Arm anthropometry in nutritional assessment. Am $\mathcal{I}$ Clin Nutr 1973;26:912-5.

24 Park NJ, Fenton JCB. A simple method for the estimation of plasma ammonia using an ion specific electrode. $\mathcal{F}$ Clin Pathol 1973;26:802-4.

25 Brodehl J, Gellissen K. Endogenous renal transport of free amino acids in infancy and childhood. Pediatrics 1968;42: 395-404.

26 Scriver CR, Davies E. Endogenous renal clearance of free amino acids in pre-pubertal children. Pediatrics 1965;36: 592-8.

27 Clayton BE, Jenkins P, Round JM. Paediatric chemical pathology. Oxford: Blackwell Scientific Publications, 1980:32.

28 Lovejoy FH, Smith AL, Bresnan MJ, Wood JN, Victor DI, Adams PC. Clinical staging in Reye syndrome. Am $\mathcal{f} D$ is Child 1974;128:36-41.

29 Busittil RW, Colanna JO II, Hiatt JR, et al. The first 100 liver transplants at UCLA. Ann Surg 1987;206:387.

30 Sherlock S. Diseases of the liver and biliary system. 8th Ed. Oxford: Blackwell Scientific Publications, 1989:717. 